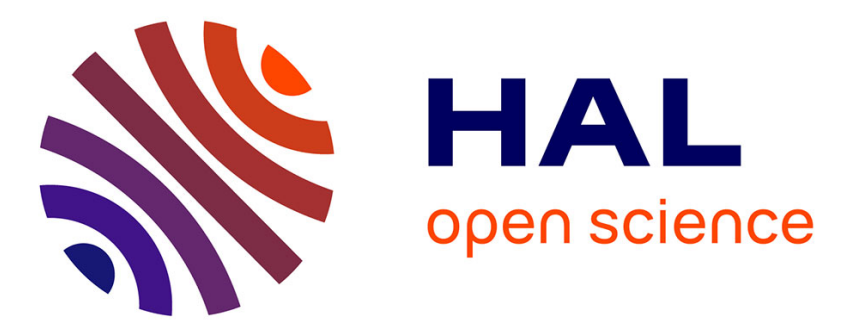

\title{
Toward Understanding Drug Incorporation and Delivery from Biocompatible Metal-Organic Frameworks in View of Cutaneous Administration
}

\author{
Sara Rojas, Isabel Colinet, Denise Cunha, Tania Hidalgo, Fabrice Salles, \\ Christian Serre, Nathalie Guillou, Patricia Horcajada
}

\section{To cite this version:}

Sara Rojas, Isabel Colinet, Denise Cunha, Tania Hidalgo, Fabrice Salles, et al.. Toward Understanding Drug Incorporation and Delivery from Biocompatible Metal-Organic Frameworks in View of Cutaneous Administration. ACS Omega, 2018, 3 (3), pp.2994 - 3003. 10.1021/acsomega.8b00185 . hal-01730569

\author{
HAL Id: hal-01730569 \\ https://hal.science/hal-01730569
}

Submitted on 25 May 2021

HAL is a multi-disciplinary open access archive for the deposit and dissemination of scientific research documents, whether they are published or not. The documents may come from teaching and research institutions in France or abroad, or from public or private research centers.
L'archive ouverte pluridisciplinaire HAL, est destinée au dépôt et à la diffusion de documents scientifiques de niveau recherche, publiés ou non, émanant des établissements d'enseignement et de recherche français ou étrangers, des laboratoires publics ou privés. 


\section{Toward Understanding Drug Incorporation and Delivery from Biocompatible Metal-Organic Frameworks in View of Cutaneous Administration}

Sara Rojas, ${ }^{\dagger}$ Isabel Colinet, ${ }^{\dagger}$ Denise Cunha, ${ }^{\dagger}$ Tania Hidalgo, $^{\dagger}$ Fabrice Salles, ${ }^{\ddagger \odot}$ Christian Serre, ${ }^{\dagger, \S}$ Nathalie Guillou, ${ }^{\dagger}$ and Patricia Horcajada*, ${ }^{\dagger}, \|_{\odot}$

${ }^{\dagger}$ Institut Lavoisier, CNRS UMR 8180, UVSQ, Université Paris-Saclay, 45, Avenue Des Etats Unis, 78035 Versailles Cedex, France

${ }^{\ddagger}$ Institut Charles Gerhardt Montpellier, CNRS UMR 5253, UM, ENSCM, Place E. Bataillon, 34095 Montpellier Cedex 05, France

${ }^{\S}$ Institut des Matériaux Poreux de Paris, FRE 2000 CNRS Ecole Normale Supérieure, Ecole Supérieure de Physique et de Chimie Industrielles de Paris, PSL Research University, 24 rue Lhomond, 75005 Paris, France

"IMDEA Energy, Avenue Ramón de la Sagra 3, 28935 Móstoles, Madrid, Spain

Supporting Information

ABSTRACT: Although metal-organic frameworks (MOFs) have widely demonstrated their convenient performances as drug-delivery systems, there is still work to do to fully understand the drug incorporation/delivery processes from these materials. In this work, a combined experimental and computational investigation of the main structural and physicochemical parameters driving drug adsorption/desorption kinetics was carried out. Two model drugs (aspirin and ibuprofen) and three water-stable, biocompatible MOFs (MIL-100(Fe), UiO-66(Zr), and MIL-127(Fe)) have been selected to obtain a variety of drug-matrix couples with different structural and physicochemical characteristics. This study evidenced that the drug-loading and drug-delivery processes are mainly governed by structural parameters (accessibility of the framework and drug volume) as well as the MOF/drug hydrophobic/hydrophilic balance. As a result, the delivery of the drug under simulated cutaneous conditions (aqueous media at $37^{\circ} \mathrm{C}$ ) demonstrated that these systems fulfill the requirements to be used as topical drug-delivery systems, such as released payload between 1 and 7 days. These results highlight the importance of the rational selection of MOFs, evidencing the effect of geometrical and chemical parameters of both the MOF and the drug on the drug adsorption and release.

\section{INTRODUCTION}

Once administered, therapeutic drugs should be in a concentration at which full efficacy is achieved with no associated side effects. ${ }^{1}$ For that purpose, several drug-delivery systems (DDS) have been formulated and/or are being investigated for drug administration (e.g., intravenous, oral, nasal). ${ }^{2,3}$ Among them, metal-organic frameworks (MOFs) have recently emerged as original promising DDS. ${ }^{4-7}$ MOFs are crystalline solids based on metal ions subunits coordinated to organic polydentate ligands, leading to the formation of highly porous structures. ${ }^{8}$ Their structural/chemical diversity and exceptional porosity (Brunauer-Emmett-Teller (BET) surface $\left(S_{\mathrm{BET}}\right)$ up to $\left.7000 \mathrm{~m}^{2} \cdot \mathrm{g}^{-1}\right)$ together with their amphiphilic internal microenvironment are thus well adapted to the adsorption of a large variety of guest molecules, including the therapeutic ones (e.g., drugs, cosmetics, biological gases, enzymes). ${ }^{4,7,9}$

Although MOFs have been extensively investigated for drug administration, ${ }^{4,7,9,10}$ the large versatility of these solids makes it difficult to predict which is the best MOF material for a given drug molecule. Although the pore size, chemical composition, and stability of MOFs play an essential role in controlling the drug incorporation/delivery processes and the total cargo capacity, ${ }^{10-13}$ studies focusing on the systematic understanding of the encapsulation and delivery processes using MOFs still remain very limited. To the best of our knowledge, only three works have focused on the understanding of the drug incorporation and delivery processes, which is crucial to improve and/or control their performances. In this regard, Maurin and co-workers have pioneered and reported a quantitative-structure activity relationship approach to predict the encapsulation rate as a function of the physicochemical properties of MOFs, validating this strategy using a series of functionalized porous flexible Fe(III) terephthalates (MIL-88B; MIL = Materials of Institut Lavoisier $)^{14}$ or functionalized rigid $\mathrm{Zr}(\mathrm{IV})$ terephthalates $(\mathrm{UiO}-66 ; \mathrm{UiO}=\text { University of Oslo })^{15}$

Received: January 30, 2018

Accepted: February 27, 2018

Published: March 12, 2018 
and two model active ingredients (caffeine and ibuprofen). The drug uptake was analyzed as a function of the polarity, polarizability, and $\mathrm{H}$-donor capacity of the functionalized organic linkers. Later, Serre and co-workers followed an experimental and computational strategy to rationalize the encapsulation and release of the cosmetic amphiphilic molecule, caffeine, highlighting the importance of the encapsulation conditions and the MOF topology and polarity on the drug uptake and delivery kinetics. ${ }^{16}$ However, all of these works are focused on the influence of the MOF properties on the drug encapsulation, and the effect of the drug nature on the encapsulation and delivery is not systematically considered. So, there is no comparative study determining the main requirements/parameters of MOFs and drug to be considered for a suitable cutaneous MOF carrier. Thus, there is still a need to better understand the mechanisms of drug incorporation and delivery, particularly the influence of the drug properties on the drug sorption processes.

Taking this into account, we have selected two topical nonsteroidal anti-inflammatory and analgesic drugs, exhibiting different physicochemical properties: (i) acetylsalicylic acid (also known as aspirin, AAS) as a hydrophilic model cargo (log $P=1.19$ ) and (ii) isobutylphenylpropanoic acid (or ibuprofen, IBU) as hydrophobic drug $(\log P=3.97)$, to analyze, through a combined experimental and computational systematic study, how these features will affect the drug adsorption/desorption kinetics in MOF matrixes. Besides, the well-known and common gastric mucosal damage of these orally administered drugs, ${ }^{17,18}$ together with their unquestioned value in the treatment of various symptoms (e.g., fever, pain) and inflammatory diseases (e.g., rheumatoid arthritis, pericarditis), shows that alternative formulations need to be undertaken. ${ }^{17,19}$ In this regard, the simple and noninvasive cutaneous route is very convenient whether for a local (topical) or systemic (transdermal) administration. ${ }^{20}$ We note here that the desired properties of MOFs for a cutaneous treatment significantly differ from those required for other administration routes (stability, delivery time, etc.). To date, MOFs have been mostly proposed for intravenous administration, ${ }^{4}$ and only three works have been reported dealing with the potential use of MOFs in cutaneous applications. The first described the use of a NOloaded Ni carboxylate CPO-27 with two different hydrocolloids (cellulose and polyisobutanol) for the topical (local) delivery of NO. ${ }^{21}$ The second is the study of Ni-CPO-27 or $\operatorname{HKUST}(\mathrm{Cu})$ nanoparticles with poly(tetrafluoroethylene) patches for the local co-delivery of $\mathrm{NO}$ and an antibiotic (metronidazole). ${ }^{22}$ Finally, Horcajada and co-workers have recently reported the skin bypass of the cosmetic caffeine by using cutaneous patches based on biocompatible MIL-100(Fe) nanoparticles associated with different biopolymers. ${ }^{23}$ Therefore, to gain further fundamental understanding, we analyze here the performances of several MOF-drug systems for the cutaneous delivery of AAS and IBU. These results will be further compared to those of the previously published studies on caffeine-containing MIL100, MIL-127, UiO-66, and MIL-53 solids. ${ }^{16}$

In addition to the MOFs and drug structural characteristics, hydrophobic/hydrophilic balance is another key parameter, taking into account that MOFs possess both a polar part (metal clusters) and a nonpolar fraction (aromatic ligands). Previous water sorption experiments provide an appropriate tool to probe the hydrophilic/hydrophobic properties of MOFs and their stability to moisture. ${ }^{24,25}$ Hence, we have selected three MOF architectures with different hydrophilic/hydrophobic balance (Figure 1): (i) the more hydrophilic mesoporous MIL-100, ${ }^{26}$ or $\left[\mathrm{Fe}_{3} \mathrm{O}\left(\mathrm{H}_{2} \mathrm{O}\right)_{2} \mathrm{OH}(\mathrm{BTC})_{2}\right] \cdot n \mathrm{H}_{2} \mathrm{O} \quad\left(\mathrm{H}_{3} \mathrm{BTC}=\right.$

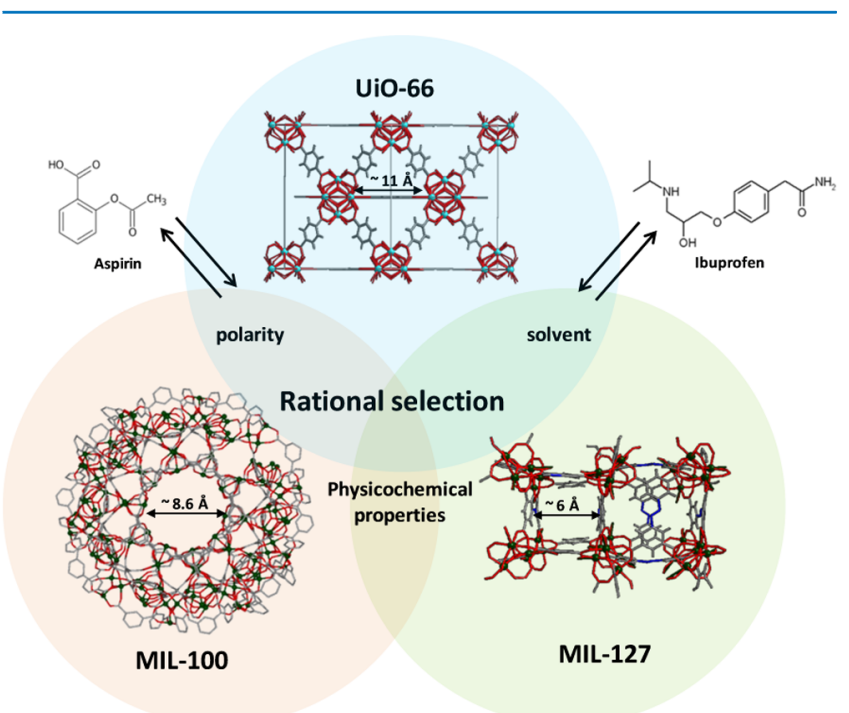

Figure 1. Schematic view of the structure of UiO-66, MIL-100, and MIL-127 (zirconium polyhedra, iron polyhedra, nitrogen, oxygen, and carbon are represented in cyan, green, blue, red, and gray, respectively; hydrogen atoms are omitted for clarity). Structures of AAS and IBU drugs are also given.

1,3,5-benzenetricarboxylic acid or trimesic acid) based on iron(III) octahedra trimers and trimesate anions leading to a very high porosity $\left(S_{\mathrm{BET}} \sim 2000 \mathrm{~m}^{2} \cdot \mathrm{g}^{-1}, V_{\mathrm{p}} \sim 1.2 \mathrm{~cm}^{3} \cdot \mathrm{g}^{-1}\right)$, associated with two types of mesoporous cages (25 and $29 \AA$ ) accessible through microporous windows (ca. 4.8-5.8 and 8.6 $\AA$, respectively); ${ }^{27}$ (ii) the microporous hydrophilic/hydrophobic MIL-127 structure, or [Fe ${ }_{3} \mathrm{O}$ $\left.(\mathrm{OH})_{0.88} \mathrm{Cl}_{0.12}\left(\mathrm{C}_{16} \mathrm{~N}_{2} \mathrm{O}_{8} \mathrm{H}_{6}\right)_{1.5}\left(\mathrm{H}_{2} \mathrm{O}\right)_{3}\right] \cdot n \mathrm{H}_{2} \mathrm{O} \quad\left(S_{\text {BET }}>1200\right.$ $\left.\mathrm{m}^{2} \cdot \mathrm{g}^{-1}, V_{\mathrm{p}} \sim 0.7 \mathrm{~cm}^{3} \cdot \mathrm{g}^{-1}\right)$ based on iron octahedra trimers and $3,3^{\prime}, 5,5^{\prime}$-azobenzenetetracarbozylate anions, associated with two types of pores, namely, an accessible hydrophobic one-dimensional (1D) channel system $(\sim 6 \AA)$ and more hydrophilic cages of $\sim 10 \AA$, accessible through narrow apertures of $\sim 3 \AA_{;}^{28,29}$ and (iii) the microporous slightly hydrophobic UiO-66 solid or $\left[\mathrm{Zr}_{6} \mathrm{O}_{4}(\mathrm{OH})_{4}(\mathrm{BDC})_{6}\right] \cdot n \mathrm{H}_{2} \mathrm{O}$ $\left(\mathrm{H}_{2} \mathrm{BDC}=1\right.$,4-benzenedicarboxilic acid $),\left(S_{\mathrm{BET}} \sim 1200 \mathrm{~m}^{2} \cdot \mathrm{g}^{-1}\right.$, $V_{\mathrm{p}} \sim 0.5 \mathrm{~cm}^{3} \cdot \mathrm{g}^{-1}$ ) based on zirconium(IV) oxoclusters and terephthalate anions, possessing octahedral and tetrahedral cavities ( $\sim 11$ and $\sim 8 \AA$, respectively) accessible through triangular micropores (ca. 5-7 $\AA$ ). ${ }^{30,31}$

\section{RESULTS AND DISCUSSION}

2.1. Drug Incorporation. The impregnation of the porous materials with ethanolic solutions of both drugs led in all cases to an efficient incorporation. The drug-loaded matrixes MIL100@AAS, MIL-100@IBU, UiO-66@AAS, UiO-66@IBU, MIL-127@AAS, and MIL-127@IBU reached a maximum capacity after $24 \mathrm{~h}$ for all MOF-drug systems. X-ray powder diffraction (XRPD) patterns evidence that the drug-loading process does not alter the crystalline structure of the porous materials (Supporting Information (SI), Figure S6). In addition, the absence of Bragg peaks corresponding to free AAS or IBU rules out the presence of free recrystallized drug out of the pores. 
Table 1. Textural Properties of MOFs before and after Drug Adsorption Process ${ }^{a}$

\begin{tabular}{|c|c|c|c|c|c|c|c|}
\hline \multirow[b]{2}{*}{ MOF } & \multirow[b]{2}{*}{ drug } & \multicolumn{2}{|c|}{ before encapsulation } & \multicolumn{2}{|c|}{ after drug encapsulation } & \multirow[b]{2}{*}{ drug wt $\%\left(\mathrm{~mol} \cdot \mathrm{mol}^{-1}\right)$} & \multirow[b]{2}{*}{ drug occupancy volume $\left(\mathrm{A}^{3} \cdot\right.$ molecule $\left.^{-1}\right)$} \\
\hline & & $V_{\mathrm{p}}\left(\mathrm{cm}^{3} \cdot \mathrm{g}^{-1}\right)$ & $S_{\text {BET }}\left(\mathrm{m}^{2} \cdot \mathrm{g}^{-1}\right)$ & $V_{\mathrm{p}}\left(\mathrm{cm}^{3} \cdot \mathrm{g}^{-1}\right)$ & $S_{\text {BET }}\left(\mathrm{m}^{2} \cdot \mathrm{g}^{-1}\right)$ & & \\
\hline \multirow[t]{2}{*}{ MIL-100 } & IBU & 1.42 & 1940 & 0.34 & 509 & $30.6 \pm 0.9(1.0)$ & $1078(474)^{b}$ \\
\hline & AAS & & & 0.57 & 1072 & $24.8 \pm 0.8(1.0)$ & $763(336)^{b}$ \\
\hline \multirow[t]{2}{*}{$\mathrm{UiO}-66$} & IBU & 0.64 & 1349 & 0.12 & 383 & $35.5 \pm 3.2(3.7)$ & 347 \\
\hline & AAS & & & 0.32 & 724 & $25.5 \pm 3.7(3.0)$ & 199 \\
\hline \multirow[t]{2}{*}{ MIL-127 } & IBU & 0.47 & 1304 & 0.09 & 105 & $13.6 \pm 0.7(0.5)$ & $1272(250)^{b}$ \\
\hline & AAS & & & 0.37 & 836 & $4.4 \pm 0.6(0.2)$ & $1224(241)^{b}$ \\
\hline
\end{tabular}

${ }^{a}$ Total drug loading (wt $\%$ and $\left.\mathrm{mol} \cdot \mathrm{mol}^{-1}\right)$ and estimated occupancy volume of a single drug molecule $\left(\mathrm{A}^{3} \cdot \mathrm{molecule}^{-1}\right) .{ }^{b}$ Estimated considering a selective occupation of the porosity.

The drug content, estimated by thermogravimetric analysis (TGA) and high-performance liquid chromatography (HPLC), was high regardless of the nature of the MOF (Table 1 and SI, Section 3). Remarkably, higher drug loadings were obtained for UiO-66, reaching up to 35.5 and 25.5 wt \% for IBU and AAS, respectively, corresponding to 3.7 and $3.0 \mathrm{~mol}$ of drug per mol of material, with high efficiencies of ca. 92 and 75\% (compared to the total drug available in the starting solution). This is particularly significant because MIL-100 and MIL-127 possess larger pore volumes than UiO-66 (Table 1). However, these results are in agreement with the previously obtained ones for the caffeine encapsulation, where the following classification from the highest to the lowest caffeine loading capacity was obtained: UiO-66 > MIL-100 > MIL-127. ${ }^{16}$ Moreover, the high IBU loading capacity for UiO-66 supported the recently published results obtained using CD-MOF-1 and the porous carbon derived from MOF PCDM-1000 (35.5 vs 26 and $32 \mathrm{wt}$ $\%$, respectively). ${ }^{32,33}$ Finally, increasing initial drug concentrations and/or successive impregnations did not lead to any improvement in the drug capacity.

The incorporation of AAS and IBU into the MIL-100, UiO66, and MIL-127 cavities was further demonstrated by the dramatic reduction of the $\mathrm{N}_{2}$ sorption capacity of the MOFs (SI, Section 4, Figure S8). In this regard, to shed some light on the influence of porosity on drug adsorption, we have estimated the volume occupied by one drug molecule inside the MOF by taking into account the variation of the MOF pore volume after the drug encapsulation and the total amount of loaded drug (SI, Section 4, eq 1). The larger occupancy volume of both drugs in MIL-100 and MIL-127 (IBU: 1078 and $797 \AA^{3}$, AAS: 1522 and $1438 \AA^{3}$, respectively) compared to the free drug molecular volume ( $\sim 372$ and $155 \AA^{3}$ for IBU and AAS, respectively, as estimated under vacuum by ChemDraw) might be due to the partial occupancy of the porosity, as confirmed by the important remaining porosity after drug insertion (Table 1). This could be related to a selective adsorption of the drug that might occur only within the larger cages of MIL-100 (accessible via hexagonal windows of $\sim 8.6 \AA$ ) and the channels of MIL$127(\sim 6 \AA)$. In contrast, the dimensions of both IBU $(11.0 \times$ $\left.5.0 \times 4.3 \AA^{3}\right)$ and AAS $\left(7.8 \times 5.8 \times 2.3 \AA^{3}\right)$ might prevent their loading into the smaller cages of MIL-100 (exclusively accessible by pentagonal windows of ca. 4.8-5.8 $\AA$ ) and the hydrophilic cages of MIL-127, accessible through apertures of 3 $\AA$ (note that van der Waals radius has been considered).

Furthermore, in the case of MIL-100, it is known that ethanol (used as solvent in the impregnation) can bind the coordinatively unsaturated iron(III) metal sites (CUS), pointing to the center of the window, then considerably reducing the free diameter of the hexagonal (from 8.2 to $4.1 \AA$ ) and pentagonal (from 4.5 to $1.7 \AA$ ) windows, and therefore, drastically reducing the diffusion of the drugs into the pores, particularly into the smaller cages. ${ }^{34}$ This suggests the absence of any encapsulation within the smaller cage of MIL-100, in agreement with the selective location of IBU within the larger cages of MIL-100(Cr), as previously proposed. ${ }^{10}$ We note here the similar IBU uptake of the Cr-based MIL-100 and its ironbased analogue (35 vs 31 wt \%), ruling out any significant influence of the metal on the drug adsorption process. Thus, excluding the drug adsorption within the smaller pores, this gives a more realistic volume of the MIL-100 occupied by IBU or AAS (44\%), corresponding to drug occupancy volumes of 474 and $336 \AA^{3}$.

A theoretical maximum loading was estimated by assuming a selective adsorption within the larger cavities of MIL-100. Such predictions, corresponding to 1.0 (IBU) and 1.6 (AAS) mol. $\mathrm{mol}^{-1}$, illustrate two different situations: in the case of IBU the maximal capacity is reached $\left(1 \mathrm{~mol} \cdot \mathrm{mol}^{-1}\right)$, whereas it is not the case for MIL-100@AAS (1.6 vs $\left.1.0 \mathrm{~mol} \cdot \mathrm{mol}^{-1}\right)$. Lin et al. ${ }^{35}$ have recently reported an exceptionally high loading of $1.8 \mathrm{~g}$ of AAS per gram of MIL-100 $\left(6.5 \mathrm{~mol} \cdot \mathrm{mol}^{-1}\right)$ with however a residual porosity of $64 \%$ after encapsulation. This high residual porosity $\left(S_{\mathrm{BET}}=1141 \mathrm{~m}^{2} \cdot \mathrm{g}^{-1}, V_{\mathrm{p}}=0.62 \mathrm{~cm}^{3} \cdot \mathrm{g}^{-1}\right)$, in agreement with a partial occupation of the MIL-100 porosity, was however not consistent with the location of the drug exclusively within the pores. Even considering a full occupancy of both cavities, the maximum theoretical amount of encapsulated AAS in MIL100 shall indeed not exceed $1.09 \mathrm{~g} \cdot \mathrm{g}^{-1}\left(3.9 \mathrm{mmol} \cdot \mathrm{mol}^{-1}\right)$. In addition, drug estimation from Lin's TGA fits better with a lower "more realistic" encapsulation rate of around $21.0 \mathrm{wt} \%$ (ca. 40 wt loss \% corresponding to both AAS and linker), in line with our results $(25.5 \mathrm{wt} \%)$.

Similarly to MIL-100, one could expect a selective adsorption of the drug within the microporous channels of MIL-127. Here, only ca. $19 \%$ of the total free volume can be occupied by IBU and AAS, which corresponds to occupancy volumes of 250 and $241 \AA^{3}$, respectively, which is also, on the whole, in agreement with the free drug volumes ( $\sim 372$ and $155 \AA^{3}$, respectively).

Estimating the theoretical maximum loading by assuming a selective adsorption within the channels, we find that the theoretical maximum AAS cargo is higher than the experimental data $\left(1.01 \mathrm{vs} 0.27 \mathrm{~mol} \cdot \mathrm{mol}^{-1}\right)$, suggesting that the maximum drug capacity is not reached. On the other hand, the experimental data of IBU adsorption $\left(0.5 \mathrm{~mol} \cdot \mathrm{mol}^{-1}\right)$ fit well with the theoretical data of IBU cargo $\left(0.42 \mathrm{~mol} \cdot \mathrm{mol}^{-1}\right)$. We note here that IBU seems to occupy a lower volume when encapsulated in MIL-127 than in the free state, suggesting an improved packing probably due to the formation of weak interactions between drug molecules and the ABTC ligand.

Finally, both UiO-66@IBU and UiO-66@AAS solids keep a significant residual porosity ( 383 and $735 \mathrm{~m}^{2} \cdot \mathrm{g}^{-1}$, respectively). 


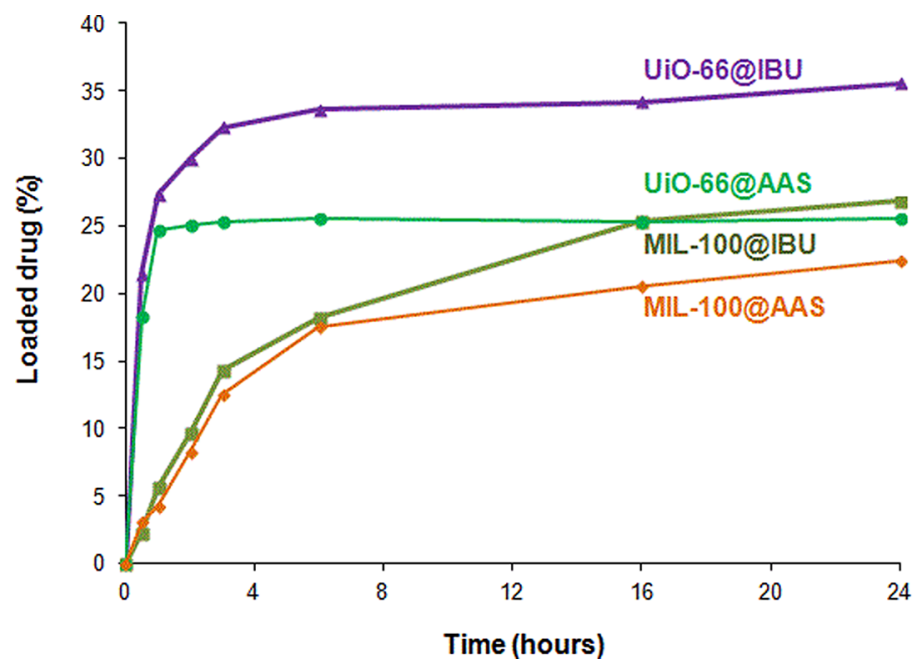

$[\mathrm{drug}]=K \mathrm{t} \quad(\mathrm{Eq} \cdot 2)$

\begin{tabular}{|c|c|c|c|c|}
\hline & \multicolumn{2}{|c|}{ IBU } & \multicolumn{2}{c|}{ AAS } \\
\hline & $\begin{array}{c}K\left(M \cdot h^{-1}\right) \\
\left(R^{2}\right)\end{array}$ & $\begin{array}{c}\text { Total drug } \\
\text { loaded } \\
(\text { wt } \%)\end{array}$ & $\begin{array}{c}K\left(M \cdot h^{-1}\right) \\
\left(R^{2}\right)\end{array}$ & $\begin{array}{c}\text { Total drug } \\
\text { loaded } \\
(w t \%)\end{array}$ \\
\hline MIL-100 & $\begin{array}{c}0.0047 \\
(\geq 0.99)\end{array}$ & 26.8 & $\begin{array}{c}0.0047 \\
(\geq 0.99)\end{array}$ & 22.4 \\
\hline UiO-66 & $\begin{array}{c}0.0295 \\
(\geq 0.88)\end{array}$ & 35.5 & $\begin{array}{c}0.0301 \\
(\geq 0.91)\end{array}$ & 25.5 \\
\hline
\end{tabular}

Figure 2. IBU (hydrophobic) and AAS (hydrophilic) encapsulation kinetics in MIL-100 (hydrophilic) and UiO-66 (hydrophobic) matrixes. Adjustment of the drug adsorption data to a zero-order kinetic equation, with different zero-order kinetic constants $(K)$, regression factors $\left(R^{2}\right)$, and total drug loadings (wt \%).

We note that octahedral and tetrahedral cavities in UiO-66 are accessible through a unique type of windows, which favors a higher loading than that in MIL-100 or MIL-127. Moreover, the presence of functional groups on the benzene ring of AAS or IBU (ester, carboxylic acids, and an alkyl side chain) might lead to various weak interactions (e.g., hydrogen bonding, van der Waals, $\pi-\pi$ staking) within the pores of UiO-66, which may further enhance their loading into the pores. This should also explain the difference between the free AAS molecular volume $\left(155 \AA^{3}\right)$ and that inside the UiO-66 framework (199 $\AA^{3}$ ) consistent with a more efficient AAS packing to minimize free volume. As an intermediate conclusion, although the pore volume and surface area of MOFs as well as the nature of solvent (see below) used for the encapsulation are key parameters to drive the encapsulation capacity, one has also to consider the correlation between the size and shape of both the pores and the drug to determine whether the drug can be adsorbed and to which extent.

Apart from these important geometrical parameters, other factors such as the chemical nature of both the MOF and the drug strongly influence the drug loading. As previously mentioned, despite the general amphiphilic character of MIL100, MIL-127, and UiO-66 solids, one could comparatively propose the following order from the more hydrophilic to the more hydrophobic material: MIL-100 > MIL-127 > UiO-66. Thus, in the case of UiO-66 and MIL-127, we observe an influence of the hydrophilic/hydrophobic balance of the matrix: the lipophilic IBU ( 3.7 and $0.5 \mathrm{~mol} \cdot \mathrm{mol}^{-1}$, respectively) is retained higher than the hydrophilic AAS (3.0 and $1.0 \mathrm{~mol}$. $\mathrm{mol}^{-1}$, respectively). In contrast, the drug uptake in the hydrophilic MIL-100 matrix does not depend on the differences of polarity of these drugs because both molecules are similarly adsorbed $\left(1.0 \mathrm{~mol} \cdot \mathrm{mol}^{-1}\right.$ in both cases $)$. Structural reasons may explain these results. The larger cage in the MIL-100 framework, in which the drug adsorption process preferentially occurs, might be large enough to allow interaction with both the hydrophobic (linker) and hydrophilic (metal trimers) parts of the pores, regardless of the nature of the cargo. These results are in agreement with the exceptional ability of this MOF to adsorb molecules bearing very different polarities (e.g., IBU (hydrophobic); caffeine and busulfan (amphiphilic); RAPTA-
C, urea, and phosphorylated nucleoside analogues (hydrophilic); etc.). ${ }^{36,37}$

To gain further understanding of the drug adsorption process, we studied in detail the solid-liquid adsorption isotherms (at $25{ }^{\circ} \mathrm{C}$ ) of IBU (hydrophobic) and AAS (hydrophilic) in the materials showing an extreme hydrophobic/hydrophilic nature: MIL-100 (hydrophilic) and UiO-66 (hydrophobic) (Figure 2). A relatively fast drug uptake was observed in all cases, with a maximum drug loading reached after $\sim 6$ and $24 \mathrm{~h}$ for UiO-66 and MIL-100, respectively. In the case of UiO-66, loadings higher than ca. 24 wt \% are even obtained during the first hour, corresponding to $97 \%$ (IBU) and $77 \%$ (AAS) of its total drug capacity. We note that the drug incorporation process in MIL-100 is prolonged, with loading rates of ca. $14 \%$ during the first $3 \mathrm{~h}$, which corresponds to total drug capacities of 53\% (IBU) and 56\% (AAS).

The data obtained after 1 or $3 \mathrm{~h}$ (UiO-66 and MIL-100, respectively) can be empirically adjusted to a zero-order kinetics (Figure 2, eq 2), where [drug] is the concentration of the drug into the ethanolic solution $(\mathrm{M})$ at equilibrium and at the time $t(\mathrm{~h})$ and $K$ is the zero-order kinetic constant $\left(\mathrm{M} \cdot \mathrm{h}^{-1}\right)$. By estimating the $K$ values, we confirmed a drug adsorption process more than 6 times faster in UiO-66 than in MIL-100, consistent with a better drug-MOF affinity. Differences in terms of pore accessibility might be at the origin of these differences. As previously mentioned, AAS and IBU fit in both octahedral and tetrahedral cavities of UiO-66, but not into the smaller cages of MIL-100. In addition, the ethanol molecules considerably reduce the accessibility of the hexagonal windows in MIL-100, through coordination on the iron metal sites pointing at the center of the windows, leading to a slower diffusion of the drug, as seen before with caffeine in MIL-100. ${ }^{16}$ Moreover, as previously studied in the use of MOFs for the separation of racemic mixtures of $( \pm)-\mathrm{IBU},{ }^{38,39}$ one expects here host-guest interactions associated with the presence of $-\mathrm{CO}_{2} \mathrm{H}$ or $\mathrm{C}=\mathrm{O}$ moieties from the drugs able to interact with the hexameric or trimeric oxoclusters of the hybrid solids. Indeed, the ${ }^{13} \mathrm{C}$ NMR spectra of the MIL-100(Cr)@IBU analogue showed previously the possible coordination of IBU to the MIL-100 structure. ${ }^{6}$ Fourier transform infrared (FTIR) spectra of both drug-loaded materials confirmed a shift in the 
wavelengths in comparison to the pure AAS and IBU, characteristic of the $\nu(\mathrm{C}=\mathrm{O})$ groups, suggesting the formation of interactions between drugs moieties and the hybrid framework (SI, Section 5, Figure S9 and Table S2). These results are in agreement with those previously published for the caffeine loaded MIL-100, UiO-66, and MIL-127, where a shift in the wavelengths of the $\nu(\mathrm{C}=\mathrm{O})$ groups of caffeine was also observed. ${ }^{16}$ Molecular simulations confirm such results when the configurations of the drugs are extracted (see Figure S16). In fact, interactions of $\mathrm{C}=\mathrm{O}$ from AAS can be observed as predominant in UiO-66. All of these results evidence the importance of the selection of the right MOF (pores and windows dimensions) to be used as DDS.

When one considers the configuration of the AAS adsorbed in MIL-127, the main interactions are between the $\mathrm{C}=\mathrm{O}$ of the drug and coordinated water molecules. This is in agreement with the saturation of metal centers with water molecules. However, in the case of IBU-loaded material, the benzene rings of the drug mainly interact with the $\mathrm{N}=\mathrm{N}$ moieties of the framework (see Figure S17). In contrast to MIL-100, $\pi$-stacking is not observed here due to the smaller pore size of MIL-127.

In conclusion, drug-matrix interactions are rather weak here. It should be noted however that our simulations do not take into account any possible coordination of the metal sites, as suggested before for MIL-100(Cr) and IBU, or the impact of the solvent, which certainly affects the nature of the drugmatrix interactions.

2.2. Drug Release. Once the porous matrixes were loaded, we evaluated their ability to deliver AAS or IBU to consider them as topical DDS. The delivery of the cargoes was performed in distilled water at $37{ }^{\circ} \mathrm{C}$, under continuous bidimensional stirring, to evaluate a potential cutaneous administration, mimicking the hydration of a cutaneous patch to evaluate and compare the delivery kinetics of these solids as a function of their features. In addition, the high stability of these MOFs might rule out any impact of the MOF degradation on the release profiles, thus allowing a better understanding of the effect of other parameters (polarity, interactions, etc.). To confirm the stability of the MOF matrixes, the leaching of ligands to the water medium was further monitored by HPLC (Figure S10), confirming the stability of all MOFs $(<2 \%)$. In particular, only $1.65,1.02$, and $0.04 \%$ of degradation were observed for UiO-66, MIL-100, and MIL-127, respectively, after 3 days, which could also correspond to the release of residual free linker initially trapped in the pores of these MOFs.

The release kinetics were determined by quantifying the amount of delivered drug in the medium by HPLC as a function of time (Figure 3). According to the drug-release profiles, the MOF-drug systems can be divided into two groups: a complete and fast release for MIL-100@IBU, MIL100@AAS, and UiO-66@AAS, against a partial and slower release for MIL-127@AAS, MIL-127@IBU, and UiO-66@IBU (Figure 3). In particular, and considering its high aqueous stability, the slow and sustained cargo release from MIL-127 is probably governed by the slow diffusion of the drugs through its 1D channels. We note that the total amounts of released drug are only $48 \pm 2 \%$ (IBU) and $37 \pm 2 \%$ (AAS) after 1 day of release. In the case of MIL-100, both drugs are released faster regardless of the nature of the cargo (hydrophilic or hydrophobic). In 1 day, MIL-100 progressively releases almost the total amount of both drugs ( $99 \pm 1$ and $84 \pm 5 \%$ of the total amount of AAS and IBU, respectively). This is likely due

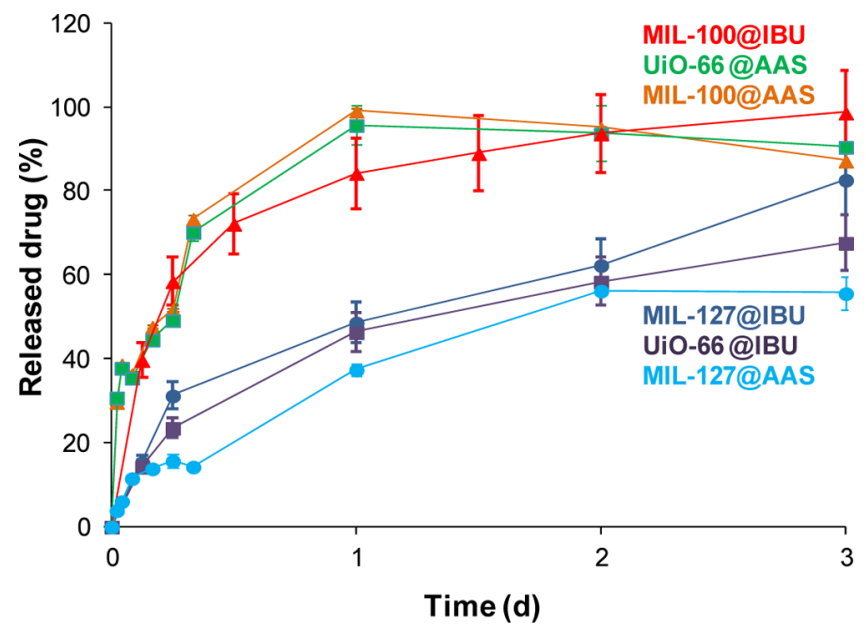

Figure 3. AAS and IBU released from the different MOFs under simulated cutaneous conditions (aqueous media at $37^{\circ} \mathrm{C}$ ).

to the larger pores (windows, cages) facilitating the diffusion of the drugs, although direct coordination of these drugs on the metal sites is likely to occur in MIL-100, as said before. In the case of UiO-66, the delivery seems more influenced by the degree of hydrophobicity of the adsorbate because a significant difference between the delivery of AAS and IBU is observed. After 1 day, UiO-66@AAS releases indeed $96 \pm 2 \%$ of the total AAS amount, whereas only $46 \pm 2 \%$ of its cargo is delivered from UiO-66@IBU. The concomitant hydrophobicities of UiO66 and IBU probably lead to even slower water diffusion into the porosity and, subsequently, a slower release of the drug. In contrast, the hydrophilic AAS molecule leads to faster delivery, similar to the one observed in MIL-100.

As a whole, one can conclude that the drug delivery in water is mainly governed by the drug hydrophobic/hydrophilic balance as well as the accessibility of the pores as highlighted here: (i) the more hydrophilic MIL-100 with very large interconnected cavities, in which the delivery process is mainly governed by the very open character of the structure (fast delivery); (ii) the hydrophobic/hydrophilic environment of MIL-127 together with narrow 1D channels (slow delivery), and finally, (iii) the more hydrophobic UiO-66 matrix with interconnected microporous cavities, leading to rather different rates of delivery, depending on the hydrophobic/hydrophilic nature of the cargo

Furthermore, the possible clinical translation of these MOF@drug systems as cutaneous DDS requires considering the total time and the total amount of the released drug. As mentioned before, specific features, differing from other administration routes, are desired for DDS for cutaneous route. In this regard, cutaneous systems are designed normally to deliver drugs from 1 to 7 days. $^{40}$ In this regard, some examples of other materials (silicon microneedles, mesoporous silica) have shown promising results in the dermal delivery of bioactive compounds (nonviral gene, methotrexate anticancer drug) for $24 \mathrm{~h}^{41,42}$ The total amounts of AAS and IBU are released from MIL-100 within 1 and 4 days, respectively (Figure S11), being of interest for the topical and/or transdermal administration of analgesic and anti-inflammatory drugs. As previously mentioned, nanoscale MIL-100 combined with different biopolymers has been recently reported for its use as cutaneous patches for the delivery of caffeine, evidencing a successful drug skin bypass dependent on the nature of the 
Table 2. Release Kinetics Including the Kinetic Model Used in the Data Fitting, the Kinetics Constant of Release, the Total Release Time, and the Total Drug Release ${ }^{a}$

\begin{tabular}{|c|c|c|c|c|c|c|}
\hline \multirow[b]{3}{*}{ material } & \multicolumn{6}{|c|}{ drug } \\
\hline & \multicolumn{3}{|c|}{ AAS } & \multicolumn{3}{|c|}{ IBU } \\
\hline & $\begin{array}{l}\text { kinetic } \\
\text { model }^{b}\end{array}$ & $k\left(\mathrm{mg} \cdot \mathrm{g}^{-1} \cdot \mathrm{h}^{-1 / 2}\right)$ & $\begin{array}{c}\text { release time (days) and delivered } \\
\text { drug (\%) }\end{array}$ & $\begin{array}{l}\text { kinetic } \\
\text { model }^{b}\end{array}$ & $k\left(\mathrm{mg} \cdot \mathrm{g}^{-1} \cdot \mathrm{h}^{-1}\right)$ or $\left(\mathrm{mg} \cdot \mathrm{g}^{-1} \cdot \mathrm{h}^{-1 / 2}\right)$ & $\begin{array}{c}\text { release time (days) and delivered } \\
\text { drug (\%) }\end{array}$ \\
\hline MIL-100 & $\mathrm{H}$ & 81.2 & $1(99 \pm 1 \%)$ & $\mathrm{H}$ & 53.2 & $4(100 \pm 2 \%)$ \\
\hline $\mathrm{UiO}-66$ & $\mathrm{H}$ & 94.7 & $1(96 \pm 2 \%)$ & $\mathrm{H}$ & 29.2 & $7(81 \pm 6 \%)$ \\
\hline MIL-127 & $\mathrm{H}$ & 2.64 & $6(61 \pm 4 \%)$ & 0 & 5.04 & $4(92 \pm 5 \%)$ \\
\hline
\end{tabular}

${ }^{a}$ Comparison of the results obtained in this study in the delivery of IBU and AAS. ${ }^{b} \mathrm{H}=$ Higuchi model; $0=$ zero-order kinetics.

biopolymer. ${ }^{23}$ We note here that IBU was released from this composite patch in a similar way to the micrometric pure MIL100 (e.g., $40 \%$ of IBU is released in $3 \mathrm{~h}$ ), suggesting that the release from the patch is mainly controlled by the MOF. UiO66-loaded materials released $96 \pm 2$ and $81 \pm 6 \%$ of the total AAS and IBU cargo in 1 and 7 days, respectively, and the MIL127@IBU and MIL-127@AAS delivered $92 \pm 5$ and $61 \pm 4 \%$ of the drug in 4 and 6 days, respectively. So, besides being biocompatible and highly stable, ${ }^{43-45}$ MIL-100, UiO-66, and MIL-127 materials are good candidates as cutaneous DDS.

The release profiles in play here lie within the same range when further compared to previous delivery studies of AAS and/or IBU from Fe-CPO-27@IBU (100\%, 4 days, phosphatebuffered saline (PBS)), ${ }^{46}$ MIL-100(Cr)@IBU (100\%, 3 days, simulated body fluid (SBF)), MIL-101(Cr)@IBU (100\%, 6 days, SBF), ${ }^{10}$ MIL-100(Fe)@AAS (33\%, 10 days, PBS; 2\%, 7 days, $\mathrm{pH} 1.2),{ }^{35}$ or $\mathrm{Zn}_{3}$ (BTC) $)_{2} @ \operatorname{IBU}\left(34 \%, 1\right.$ day, PBS), ${ }^{47}$ except for the flexible MOFs, in which much longer delivery times were observed: MIL-53(Cr)@IBU (100\%, 18 days, SBF) and MIL-53(Fe)@IBU (100\%, 20 days, SBF). ${ }^{48}$ However, as most of the studies described in the literature were performed under different conditions (e.g., simulated gastric conditions ( $\mathrm{pH}$ 1.2) or intravenous conditions (e.g., PBS, SBF)), a direct comparison is not possible because it is known that the composition of the media (e.g., ions, proteins) strongly affects the drug release kinetics.

On the basis of the previous drug-delivery results obtained with the amphiphilic cosmetic caffeine and the ones obtained here for the AAS and IBU, we can further see the influence of the nature of the active pharmaceutical ingredient on the delivery process. In this regard, when one considers studies dealing with the delivery of caffeine from MIL-100, UiO-66, and MIL-127 in water at $37{ }^{\circ} \mathrm{C}$, similar results (from fast to slow release: MIL-100 $\geq$ UiO-66 $\geq$ MIL-127) were obtained. ${ }^{16}$ This indicates that the delivery from MIL-100 and MIL-127 is less affected by the hydrophilic/hydrophobic balance of the adsorbate, whereas in the cases of UiO-66, the nature of the adsorbate molecule strongly determines its interaction with the matrix and, consequently, its release. When comparing all studied drugs in the case of UiO-66, the release rate can indeed be classified as follows (from the faster to the slower): AAS (hydrophilic, 1 day) > caffeine (amphiphilic, 2 days) $\gg$ IBU (hydrophobic, 7 days).

To shed some light on the release kinetics and to gain further understanding on the involved mechanism, the first hours of delivery (up to $1 \mathrm{~h}$ for AAS and $6 \mathrm{~h}$ for IBU) were fitted to a mathematical model. In particular, the Higuchi model, which defines the short time behavior of the release of a dispersed drug from a homogeneous matrix, ${ }^{49}$ has been used to describe the diffusion of drugs from porous materials. ${ }^{6,50,51}$ This commonly used equation perfectly describes release processes through which the drug is dispersed in stable monolithic systems (with no changes during the release process, which is the case when using these aqueous stable MOFs), being the release purely controlled by diffusion. ${ }^{49,52}$ Considering that the external diffusion process around the MOF particles is minimized by continuous stirring during the delivery assay, the desorption process is only due to the drug movements through the pores of the frameworks. Therefore, the AAS and IBU delivery from the studied matrixes can be explained by the following equation

$$
[\operatorname{drug}]=K \cdot t^{1 / 2}
$$

where $[\mathrm{drug}]$ corresponds to the concentration of released drug $\left(\mathrm{mg} \cdot \mathrm{g}^{-1}\right), t$ is the time $(\mathrm{h})$, and $K$ is the kinetic constant ( $\mathrm{g}$. $\left.\mathrm{mg}^{-1} \cdot \mathrm{h}^{-1 / 2}\right)$.

Except for MIL-127@IBU, with regression factor $\left(R^{2}\right)$ value slightly below 0.99 , the rest of the drug releases can be empirically adjusted in the first hour (AAS) and the sixth hour (IBU) to the Higuchi model with $R^{2}>0.99$ (Table 2; Figure S12). Therefore, the drug release is here mainly governed by a diffusion process, predictable by the Higuchi model and dependent on several factors such as the structure (dimensionality, interconnectivity, pore size) and composition (polarity, interactions). The initial delivery rate can be easily compared by estimating the constant diffusion coefficients (Table 2), observing the following classification from the faster to the slower initial release kinetics: UiO-66@AAS > MIL-100@AAS $\gg$ MIL-100@IBU $\gg$ UiO-66@IBU $\gg>$ MIL-127@IBU $\gg>$ MIL-127@AAS. In addition, kinetic constants associated with the IBU delivery are always lower than those of AAS, in agreement with the hydrophobicity of IBU.

In the particular case of MIL-127@IBU, a better fit can be obtained by using a zero-order kinetic

$$
[\text { drug }]=K \cdot t
$$

where [drug] corresponds to the concentration of released drug $\left(\mathrm{mg} \cdot \mathrm{g}^{-1}\right), t$ is the time $(\mathrm{h})$, and $K$ is the kinetic constant ( $\mathrm{g}$. $\mathrm{mg}^{-1} \cdot \mathrm{h}^{-1}$, Figure S12). This means that the release process takes place at a constant rate, regardless of the remaining drug concentration, with an incomplete release of $92 \%$. Therefore, it can be assumed that MIL-127 leads to a well-controlled drug release, which might be associated to a good control of drug concentration and higher efficacy.

Taking into account that optimal cutaneous systems are designed to deliver drugs from 1 to 7 days, the structural stability of the obtained matrixes after 3 days of delivery (denoted as MOF@drug_del) and the evaluation of the residual amount of drug were studied by XRPD, FTIR, TGA, and $\mathrm{N}_{2}$ sorption measurements. In the MIL-100 materials after drug delivery, the absence of vibrational bands at around 1697 
and $1694 \mathrm{~cm}^{-1}$, characteristic of the $(\mathrm{C}=\mathrm{O})$ groups of AAS and IBU, respectively, confirms the complete release of both drugs (Figure S13). These results are in agreement with the TGA, exhibiting a similar composition to the starting material considering $1 \%$ of matrix degradation (Figures S10 and S14, Table S3). The structural integrity of MIL-100@drug_del in water after 3 days monitored by XRPD indicates a partial loss of crystallinity, probably due to the creation of some defects within the matrix or the difference in the water content (Figure S15). Furthermore, $\mathrm{N}_{2}$ sorption experiments of MIL-100@ AAS del confirm the complete recovery of the porosity after the delivery of the cargo (Figure S16). In contrast, the porosity of MIL-100 is not completely recovered after the release of IBU. This discrepancy may find its origin in a partial amorphization of the framework and may be misleading because crystallinity might be retained while a part of the solid is degraded (amorphization, hydrolysis, or residual traces of IBU that block the access to the porosity).

On the other hand, the FTIR spectrum of UiO-66@IBU del shows a vibrational band at around $1700 \mathrm{~cm}^{-1}$, which could be assigned to the $\nu(\mathrm{C}=\mathrm{O})$ groups of IBU or even the BDC ligand (Figure S13). It is known that the BDC ligand shows a low solubility in water $\left(25^{\circ} \mathrm{C}, 1.7 \mathrm{mg} \cdot 100 \mathrm{~mL}^{-1}\right)$. However, the HPLC measurements confirm that only $1.65 \%$ of the total BDC is released after $24 \mathrm{~h}$ in water, ruling out the presence of the ligand and supporting the presence of residual traces of drug. TGA indicates that the residual drug contents are about 9 and 35\% for UiO-66@AAS_del and UiO-66@IBU_del, respectively (Figure S14, Table S3). These results are in good agreement with the total amount of released drug after 3 days from the UiO-66 material, as studied by HPLC ( $96 \pm 2 \%$ of AAS and 68 $\pm 3 \%$ of IBU). After drug release, XRPD patterns showed that the structural stability is maintained, although a partial loss of crystallinity or disorder into the pores of the matrix is observed (Figure S15). The presence of residual drug molecules inside the UiO-66 matrixes might explain the reduction of the $\mathrm{N}_{2}$ uptake at $77 \mathrm{~K}$ after the drug-delivery process compared to the pristine materials (Figure S16). After the drug delivery, 64\% (UiO-66@IBU_del) and 88\% (UiO-66@AAS_del) of the pore volume are recovered, values near to the expected values of 68 and $96 \%$ of the IBU and AAS release, respectively (Table S4).

Finally, for MIL-127, both drugs are only partially released. In the case of MIL-127@AAS_del, the amount of remaining drug inside the pores is rather high, i.e., $53 \%$, deduced from HPLC (Figure S11), IR spectra (see band at ca. $1700 \mathrm{~cm}^{-1}$ on Figure S13), TGA (around 50\% of residual AAS, Figure S14, Table S3), and BET (see lower surface area in Figure S16) with only $62 \%$ of the pore volume recovered, which is close to the expected pore volume (84\%, Table S4). Similarly, MIL-127@ IBU_del also contains residual IBU but to a much lower extent than with AAS, i.e., around $18 \%$. This is confirmed by IR spectra (see band at $1703 \mathrm{~cm}^{-1}$ in Figure S13), TGA, and HPLC (Figure S14, Table S3). As the percentage of residual IBU is here rather low, the $\mathrm{N}_{2}$ uptake at $77 \mathrm{~K}$ after IBU release is higher, although not totally recovered ( $74 \%$ of the initial pore volume, see Table S4). In both cases, the structural integrity of the MOF is kept after release, as shown by XRPD patterns (Figure S15). Therefore, one can conclude that MIL-127 remains stable during the delivery process, which makes this material interesting for its potential use as cutaneous drugdelivery system.

\section{CONCLUSIONS}

To gain further understanding of the drug adsorption and delivery from MOFs, three rigid MOF architectures with different hydrophilic/hydrophobic balance have been selected for the encapsulation and release of two model drugs. The loadings of the hydrophilic aspirin and the hydrophobic ibuprofen have been performed in the MIL-100, UiO-66, and MIL-127 structures, resulting in six different loaded matrixes. One could establish that the drug uptake is here governed by the hydrophilic/hydrophobic balance between cargo and matrix (UiO-66 and MIL-127) and the accessibility of the drug through the framework (MIL-100 and MIL-127). Their controlled release under cutaneous conditions follows different kinetics profiles depending on: (i) the structure of the framework, with either a fast delivery from the very open structure MIL-100 or a slower drug release from the narrow 1D pore system of MIL-127 or (ii) the hydrophobic/hydrophilic nature of the cargo, with a fast (AAS) and slow (IBU) release from the UiO-66 matrix.

As a whole, all loaded materials fit well as cutaneous drugdelivery systems because of their high drug loading and good aqueous stability, which is associated with drug releases in less than 7 days. These results highlight the importance on the rational selection of MOFs and the physicochemical properties of cargoes on the encapsulation and release process.

\section{EXPERIMENTAL SECTION}

All reactants were commercially obtained and used without further purification. The synthesis of starting materials was performed under solvothermal or reflux conditions following similar procedures as previously reported.

4.1. Synthesis of Ethyl Ester 1,3,5-Benzenetricarboxylic (EE-BTC). 1,3,5-Benzenetricarboxylic acid $\left(\mathrm{H}_{3} \mathrm{BTC} ; 5 \mathrm{~g}\right.$, $2.4 \mathrm{mmol}$ ) was dispersed in $100 \mathrm{~mL}$ of absolute ethanol. $\mathrm{H}_{2} \mathrm{SO}_{4}$ $(95 \%, 2 \mathrm{~mL})$ was added to this suspension, and the resulting mixture was stirred under reflux for $24 \mathrm{~h}$ to give, upon cooling, a white precipitate, which was filtered off (filter funnel no. 4) and cleaned with water and ether. ${ }^{1} \mathrm{H}$ NMR $(300 \mathrm{MHz}$, $\left.\mathrm{CDCl}_{3}\right) \delta: 8.84(\mathrm{~s}, 3 \mathrm{H}), 4.45(\mathrm{q}, 6 \mathrm{H}), 1.43(\mathrm{t}, 9 \mathrm{H})$.

4.2. Synthesis of $3,3^{\prime}, 5,5^{\prime}$-Azobenzenetetracarboxylic Acid (ABTC). ${ }^{53}$ 5-Nitroisophthalic acid $(19 \mathrm{~g})$ was dispersed in $250 \mathrm{~mL}$ of distilled water. $\mathrm{NaOH}(50 \mathrm{~g})$ was added, and the resulting mixture was heated at $60{ }^{\circ} \mathrm{C}$ under stirring. A pink slurry was thus formed. Subsequently, $100 \mathrm{~g}$ of glucose dissolved in $150 \mathrm{~mL}$ of water was slowly added to the previously obtained pink slurry. The solution turned from yellow to orange and then to brown. The heating was stopped, and air was bubbled through the solution overnight at room temperature. The mixture was then cooled with an ice bath to optimize the amount of precipitate, before recovering the disodium salt by filtration. The filtrate was then redissolved in $200 \mathrm{~mL}$ of distilled water and then this solution was acidified to $\mathrm{pH}=1$ using $\mathrm{HCl}$ (37\%). This yielded a bright orange precipitate, which was recovered by filtration and washed with ethanol. ${ }^{1} \mathrm{H}$ NMR (DMSO- $\left.d_{6}\right) \delta: 8.62(6 \mathrm{H})$.

4.3. Synthesis of MIL-100 $\left[\mathrm{Fe}_{3} \mathrm{O}\left(\mathrm{H}_{2} \mathrm{O}\right)_{2} \mathrm{OH}\left(\mathrm{C}_{9} \mathrm{H}_{3} \mathrm{O}_{6}\right)_{2}\right] \cdot$ $n \mathrm{H}_{2} \mathrm{O}^{27} \mathrm{FeCl}_{3} \cdot 6 \mathrm{H}_{2} \mathrm{O}(2.7 \mathrm{~g}, 10 \mathrm{mmol})$ and EE-BTC $(2.24 \mathrm{~g}$, $6.66 \mathrm{mmol}$ ) were dispersed in $50 \mathrm{~mL}$ of $\mathrm{H}_{2} \mathrm{O}$. The mixture was placed in a Teflon-lined autoclave at $130{ }^{\circ} \mathrm{C}$ for 3 days. Then, the orange solid was recovered by filtration and washed with absolute ethanol $(3 \times 10 \mathrm{~mL})$. The solid was then suspended in $1 \mathrm{~L}$ of EtOH, refluxed under stirring for $3 \mathrm{~h}$, and then the same 
procedure was carried out in deionized water. The solid was recovered by filtration. The particle size is $\sim 460 \pm 80 \mathrm{~nm}$ (polydispersity index (PdI) > 0.3).

4.4. Synthesis of UiO-66 $\left[\mathrm{Zr}_{6} \mathrm{O}_{4}(\mathrm{OH})_{4}\left(\mathrm{C}_{8} \mathrm{O}_{4} \mathrm{H}_{4}\right)_{6}\right]$. $n \mathrm{H}_{2} \mathrm{O}^{15,54,55} \mathrm{ZrCl}_{4}(0.23 \mathrm{~g}, 1 \mathrm{mmol})$ and terephthalic acid $\left(\mathrm{H}_{2} \mathrm{BDC} ; 0.16 \mathrm{~g}, 1 \mathrm{mmol}\right)$ were dispersed in $3 \mathrm{~mL}$ of dimethylformamide (DMF) placed in a Teflon-lined autoclave and heated at $220{ }^{\circ} \mathrm{C}$ for $12 \mathrm{~h}$. The resulting solid was recovered by filtration. After filtration, activation was carried out by solvent exchange by suspending $200 \mathrm{mg}$ of solid in 100 $\mathrm{mL}$ of DMF under stirring for $12 \mathrm{~h}$ and then in $100 \mathrm{~mL}$ of $\mathrm{MeOH}$ under stirring for $12 \mathrm{~h}$. The particle size is $\sim 240 \pm 40$ nm $(\mathrm{PdI}>0.3)$.

4.5. Synthesis of $\mathrm{MIL-127} \quad\left[\mathrm{Fe}_{3} \mathrm{O}-\right.$ $\left.(\mathrm{OH})_{0.88} \mathrm{Cl}_{0.12}\left(\mathrm{C}_{16} \mathbf{N}_{2} \mathrm{O}_{8} \mathrm{H}_{6}\right)_{1.5}\left(\mathrm{H}_{2} \mathrm{O}\right)_{3}\right] \cdot \boldsymbol{n}\left(\mathrm{H}_{2} \mathrm{O}\right){ }^{29} \mathrm{Fe}\left(\mathrm{ClO}_{4}\right)_{3}$. $n \mathrm{H}_{2} \mathrm{O}(9.9 \mathrm{~g}, 28 \mathrm{mmol})$ and $\mathrm{ABTC}(5.0 \mathrm{~g}, 14 \mathrm{mmol})$ were dispersed in $100 \mathrm{~mL}$ of DMF. The mixture was refluxed under stirring at $150{ }^{\circ} \mathrm{C}$ for $20 \mathrm{~h}$. The solid was recovered as a brown crystalline solid by filtration and washed with EtOH. The solid was then suspended in $1 \mathrm{~L}$ of EtOH and refluxed overnight under stirring. Then, the solid was recovered by filtration. The particle size is $\sim 2 \pm 1 \mu \mathrm{m}$ ( $\mathrm{PdI}>0.3)$.

4.6. Drug Encapsulation. Ibuprofen or aspirin was entrapped into the porous solids by suspending the previously dehydrated powdered MOFs $\left(100^{\circ} \mathrm{C}\right.$ /overnight $)$ in $20 \mathrm{~mL}$ of a $20 \mathrm{mg} \cdot \mathrm{mL}^{-1}$ drug solution in ethanol at room temperature under magnetic stirring for $24 \mathrm{~h}$, using $30 \mathrm{~mL}$ vessels with magnetic stirring $(300 \mathrm{rpm})$. In all cases, the MOF/drug ratio was $1: 4$. The drug-loaded materials were recovered by filtration (filter funnel no. 4) and cleaned with $5 \mathrm{~mL}$ of ethanol.

The amount of adsorbed drug was quantified by thermogravimetric analysis (TGA) and high-performance liquid chromatography (HPLC). Pristine solids and drug-encapsulated solids were characterized by X-ray powder diffraction (XRPD), Fourier transform infrared spectroscopy (FTIR), and $\mathrm{N}_{2}$ sorption measurements.

For the evaluation of the kinetics of the drug adsorption within the MIL-100 and UiO-66, the concentration of the remaining free drug in the impregnation solution was checked by HPLC at different times (0.5, 1, 2, 3, 6, 16, 24, and $72 \mathrm{~h}$ ).

4.7. Drug Release. Drug-containing material $(5 \mathrm{mg})$ was placed in $40 \mathrm{~mL}$ of deionized water at $37{ }^{\circ} \mathrm{C}$ under bidimensional continuous stirring $(80 \times 80 \mathrm{rpm})$. At different incubation times, $20 \mathrm{~mL}$ of supernatant was recovered by centrifugation (10 500 rpm for $15 \mathrm{~min}$ ) and replaced with the same volume of fresh deionized water at $37^{\circ} \mathrm{C}$. This procedure was performed in triplicate. The amount of released drug was determined by HPLC. After the drug-delivery process, the samples were characterized by XRPD, FTIR spectroscopy, TGA, and $\mathrm{N}_{2}$ sorption.

4.8. HPLC Measurement Conditions. The amount of encapsulated and released drug, as well as the release of the corresponding organic linker was determined using a reversedphase HPLC system Waters Alliance e2695 Separations Module (Waters, Milford, MA), equipped with a variablewavelength photodiode array detector Waters 2998 and controlled by Empower software. SunFire-C18 reverse-phase column $\left(5 \mu \mathrm{m}, 4.6 \times 150 \mathrm{~mm}^{2}\right.$, Waters $)$ or Hypersil GOLD C18 $\left(5 \mu \mathrm{m}, 150 \times 4.6 \mathrm{~mm}^{2}\right.$, Thermo Fisher $)$ were employed. For the quantification of all of the chemical species, isocratic conditions were used. The flow rate was $0.8 \mathrm{~mL} \cdot \mathrm{min}^{-1}$, and the column temperature was fixed at $25{ }^{\circ} \mathrm{C}$. In all cases, the injection volume was $50 \mu \mathrm{L}$.
Different HPLC measurement conditions were used for the quantification of drugs and ligands: AAS (85:15 MeOH/buffer solution $(0.04 \mathrm{M}, \mathrm{pH}=2.5)$, retention time $(\mathrm{RT})=5.6 \mathrm{~min}$ and absorption maximum $\lambda=227.9 \mathrm{~nm})$; IBU $(85: 15 \mathrm{MeOH} /$ buffer solution $(0.04 \mathrm{M}, \mathrm{pH}=2.5), \mathrm{RT}=4.9 \mathrm{~min}$ and $\lambda=219.6$ $\mathrm{nm}) ; \mathrm{H}_{3} \mathrm{BTC}(50: 50 \mathrm{MeOH} /$ buffer solution $(0.04 \mathrm{M}, \mathrm{pH}=$ $2.5)$, $\mathrm{RT}=3.3 \mathrm{~min}$ and $\lambda=225 \mathrm{~nm}) ; \mathrm{H}_{2} \mathrm{BDC}(5: 95 \mathrm{MeOH} /$ buffer solution $(0.04 \mathrm{M}, \mathrm{pH}=9), \mathrm{RT}=3.6 \mathrm{~min}$ and $\lambda=240$ $\mathrm{nm})$; $\operatorname{ABTC}(5: 95 \mathrm{MeOH} /$ buffer solution $(0.04 \mathrm{M}, \mathrm{pH}=9)$, $\mathrm{RT}=2.9 \mathrm{~min}$ and $\lambda=225 \mathrm{~nm}$ ) (SI, Section 1; Figures S1-S5).

4.8.1. Preparation of the Buffer Solution $(0.04 \mathrm{M}, \mathrm{pH}=$ 2.5). $\mathrm{NaH}_{2} \mathrm{PO}_{4}(2.4 \mathrm{~g}, 0.02 \mathrm{~mol})$ and $\mathrm{Na}_{2} \mathrm{HPO}_{4}(2.84 \mathrm{~g}, 0.02$ mol) were dissolved in $1 \mathrm{~L}$ of Milli-Q water. The $\mathrm{pH}$ was then adjusted to 2.5 with $\mathrm{H}_{3} \mathrm{PO}_{4}(\geq 85 \%)$.

${ }^{1} \mathrm{H}$ NMR spectra for the characterization of the synthesized ligands were recorded on an Bruker Avance Instrument (300 $\mathrm{MHz}$ ). FTIR spectra were recorded using a Nicolet 6700 FTIR Thermo Scientific spectrometer in the $400-4000 \mathrm{~cm}^{-1}$ region. XRPD patterns were collected in a Siemens D5000 diffractometer $(\theta-2 \theta)$ using $\mathrm{Cu} \mathrm{K} \alpha$ radiation with a step size of $0.04^{\circ}(2 \theta)$ and $4 \mathrm{~s}$ per step in continuous mode. TGA was performed under oxygen flow $\left(20 \mathrm{~mL} \cdot \mathrm{min}^{-1}\right)$ using a PerkinElmer Diamond TGA/DTA STA 6000 running from room temperature to $600{ }^{\circ} \mathrm{C}$ with a scan rate of $2{ }^{\circ} \mathrm{C} \cdot \mathrm{min}^{-1} \cdot \mathrm{N}_{2}$ isotherms were obtained at $77 \mathrm{~K}$ using a BELSORP-mini (Bel, Japan). Prior to the analysis, approximately $40-60 \mathrm{mg}$ of material was evacuated under vacuum at different times and temperatures taking into account the decomposition temperature of AAS $\left(140{ }^{\circ} \mathrm{C}\right)$ and $\mathrm{IBU}\left(160^{\circ} \mathrm{C}\right)$; the drug-loaded materials and the materials obtained after the drug-delivery process were evacuated at $110{ }^{\circ} \mathrm{C}$ for $24 \mathrm{~h}$. HPLC measurements were performed using a HPLC system Waters Alliance e2695 Separations Module (Waters, Milford, MA) equipped with a variable-wavelength photodiode array detector Waters 2998 and controlled by Empower software.

4.9. Computational Section. To estimate the configuration of the drug molecules in the selected solids, Grand Canonical Monte Carlo (GCMC) calculations were performed at $300 \mathrm{~K}$ with a simulation box large enough to use a cutoff equal to $12.5 \AA$ with typically $10 \times 10^{6}$ Monte Carlo steps for both equilibration and production steps. Partial charges have been evaluated using qEq method (included in Materials Studio software), ${ }^{56}$ whereas universal force field is considered for Lennard-Jones interatomic potentials. ${ }^{57}$

Initial structures for MIL-100, MIL-127, and UiO-66 were obtained from the literature and then optimized classically. ${ }^{27,28,58}$ Regarding GCMC calculations, the structure of the solid was supposed to be rigid with fixed unit cell parameters. The adsorbed drug molecules were optimized using density functional theory ( $\mathrm{DMol}^{3}$ using PW91 functional and DNP basis set) calculations and considered in the GCMC calculations as rigid. We note also that drug coordination to the metal sites was not taken into consideration.

In complement, from the solid structures, free volume was calculated using a method of trial insertions within the entire volume of the unit cell. A probe size of $0 \AA$ was used to enable us to determine this total free volume of the unit cell that was not occupied by the atoms of the framework. ${ }^{59}$ The maximum saturation loading for UiO-66 and ibuprofen was determined by dividing the free volume of the structure by the volume of the IBU molecule $\left(212 \AA^{3}\right.$ determined using software available in Materials Studio). In addition, specific surface area can be calculated for each structure using the approach developed by 
Düren et al., ${ }^{59}$ considering the center of a $\mathrm{N}_{2}$ probe molecule rolling across the surface (with a diameter equal to $3.681 \AA$ ).

\section{ASSOCIATED CONTENT}

\section{S Supporting Information}

The Supporting Information is available free of charge on the ACS Publications website at DOI: 10.1021/acsomega.8b00185.

HPLC determinations, characterization of all materials (PXRD, FTIR spectroscopy, TGA, and $\mathrm{N}_{2}$ sorption measurements), stability studies, and complete drugdelivery studies (PDF)

\section{AUTHOR INFORMATION}

\section{Corresponding Author}

*E-mail: patricia.horcajada@imdea.org.

\section{ORCID}

Sara Rojas: 0000-0002-7874-2122

Fabrice Salles: 0000-0001-8069-533X

Patricia Horcajada: 0000-0002-6544-5911

\section{Notes}

The authors declare no competing financial interest.

\section{ACKNOWLEDGMENTS}

This work was supported by EU funding through the ERC2007-209241-BioMOFs ERC. S.R. acknowledges the Marie Sklodowska-Curie Programme (MSCA-IF-EF-ST-2015705529). PH acknowledges the Spanish Ramon y Cajal Programme (grant agreement no. 2014-16823) and the People Programme (Marie Curie Actions) of the European Union's Seventh Framework Programme (FP7/2007-2013) under REA grant agreement no. 291803.

\section{REFERENCES}

(1) Chien, Y. W.; Lin, S. Drug Delivery: Controlled Release. In Encyclopedia of Pharmaceutical Technology; Swarbrick, J., Ed.; CRC Press, 2007; pp 1082-1103.

(2) Qu, H.; Bhattachayya, S.; Ducheyne, P. Sol-Gel Processed Oxide Controlled Release Materials. In Comprehensive Biomaterials I; Ducheyne, P.; Ducheyne, P.; Healy, K.; Hutmacher, D. E.; Grainger, D. W.; Kirkpatrick, C. J., Eds.; Elsevier, 2011; pp 476-493.

(3) Malmsten, M. Soft Drug Delivery Systems. Soft Matter 2006, 2, $760-769$.

(4) Giménez-Marqués, M.; Hidalgo, T.; Serre, C.; Horcajada, P. Nanostructured Metal-organic Frameworks and Their Bio-Related Applications. Coord. Chem. Rev. 2015, 307, 1-19.

(5) Imaz, I.; Rubio-Martínez, M.; An, J.; Solé-Font, I.; Rosi, N. L.; Maspoch, D. Metal-Biomolecule Frameworks (MBioFs). Chem. Commun. 2011, 47, 7287-7302.

(6) Horcajada, P.; Serre, C.; Vallet-Regí, M.; Sebban, M.; Taulelle, F.; Férey, G. Metal-Organic Frameworks as Efficient Materials for Drug Delivery. Angew. Chem., Int. Ed. 2006, 45, 5974-5978.

(7) He, C.; Liu, D.; Lin, W. Nanomedicine Applications of Hybrid Nanomaterials Built from Metal-Ligand Coordination Bonds: Nanoscale Metal-Organic Frameworks and Nanoscale Coordination Polymers. Chem. Rev. 2015, 115, 11079-11108.

(8) Zhou, H.-C. J.; Kitagawa, S. Metal-Organic Frameworks (MOFs). Chem. Soc. Rev. 2014, 43, 5415-5418.

(9) Carné, A.; Carbonell, C.; Imaz, I.; Maspoch, D. Nanoscale MetalOrganic Materials. Chem. Soc. Rev. 2011, 40, 291-305.

(10) Horcajada, P.; Serre, C.; Vallet-Regí, M.; Sebban, M.; Taulelle, F.; Férey, G. Metal-Organic Frameworks as Efficient Materials for Drug Delivery. Angew. Chem., Int. Ed. 2006, 45, 5974-5978.
(11) Sun, C.-Y.; Qin, C.; Wang, X.-L.; Su, Z.-M. Metal-Organic Frameworks as Potential Drug Delivery Systems. Expert Opin. Drug Delivery 2013, 10, 89-101.

(12) Carmona, F. J.; Rojas, S.; Sánchez, P.; Jeremias, H.; Marques, A. R; Romão, C. C.; Choquesillo-Lazarte, D.; Navarro, J. A. R; Maldonado, C. R.; Barea, E. Cation Exchange Strategy for the Encapsulation of a Photoactive CO-Releasing Organometallic Molecule into Anionic Porous Frameworks. Inorg. Chem. 2016, 55, $6525-6531$

(13) Oh, H.; Li, T.; An, J. Drug Release Properties of a Series of Adenine-Based Metal-Organic Frameworks. Chem. - Eur. J. 2015, 21, 17010-17015.

(14) Gaudin, C.; Cunha, D.; Ivanoff, E.; Horcajada, P.; Chevé, G.; Yasri, A.; Lobet, O.; Serre, C.; Maurin, G. A Quantitative Structure Activity Relationship Approach to Probe the Influence of the Functionalization on the Drug Encapsulation of Porous Metal-Organic Frameworks. Microporous Mesoporous Mater. 2012, 157, 124-130.

(15) Cunha, D.; Gaudin, C.; Colinet, I.; Horcajada, P.; Maurin, G.; Serre, C. Rationalization of the Entrapping of Bioactive Molecules into a Series of Functionalized Porous Zirconium Terephthalate MOFs. J. Mater. Chem. B 2013, 1, 1101-1108.

(16) Cunha, D.; Yahia, M. B.; Hall, S.; Miller, S. R.; Chevreau, H.; Elka, E.; Maurin, G.; Horcajada, P.; Serre, C. Rationale of Drug Encapsulation and Release from Biocompatible Porous MetalOrganic Frameworks. Chem. Mater. 2013, 25, 2767-2776.

(17) Lanza, F.; Royer, G.; Nelson, R. An Endoscopic Evaluation of the Effects of Non-Steroidal Anti-Inflammatory Drugs on the Gastric Mucosa. Gastrointest. Endosc. 1975, 21, 103-105.

(18) Schoen, R. T.; Vender, R. J. Mechanisms of Nonsteroidal AntiInflammatory Drug-Induced Gastric Damage. Am. J. Med. 1989, 86, 449-458.

(19) Ammar, H. O.; Ghorab, M.; El-Nahhas, S. A.; Kamel, R. Design of a Transdermal Delivery System for Aspirin as an Antithrombotic Drug. Int. J. Pharm. 2006, 327, 81-88.

(20) Prausnitz, M. R.; Langer, R. Transdermal Drug Delivery. Nat. Biotechnol. 2008, 26 (11), 1261-1268.

(21) Horcajada, P.; Gref, R.; Baati, T.; Allan, P. K.; Maurin, G.; Couvreur, P.; Férey, G.; Morris, R. E.; Serre, C. Metal-Organic Frameworks in Biomedicine. Chem. Rev. 2012, 112, 1232-1268.

(22) McKinlay, A. C.; Allan, P. K.; Renouf, C. L.; Duncan, M. J.; Wheatley, P. S.; Warrender, S. J.; Dawson, D.; Ashbrook, S. E.; Gil, B.; Marszalek, B.; Düren, T.; Williams, J. J.; Charrier, C.; Mercer, D. K.; Teat, S. J.; Morris, R. E. Multirate Delivery of Multiple Therapeutic Agents from Metal-Organic Frameworks. APL Mater. 2014, 2, No. 124108.

(23) Márquez, A. G.; Hidalgo, T.; Lana, H.; Cunha, D.; BlancoPrieto, M. J.; Álvarez-Lorenzo, C.; Boissière, C.; Sánchez, C.; Serre, C.; Horcajada, P. Biocompatible Polymer-metal-organic Framework Composite Patches for Cutaneous Administration of Cosmetic Molecules. J. Mater. Chem. B 2016, 4, 7031-7040.

(24) Canivet, J.; Fateeva, A.; Guo, Y.; Coasne, B.; Farrusseng, D. Water Adsorption in MOFs: Fundamentals and Applications. Chem. Soc. Rev. 2014, 43, 5594-5617.

(25) Cychosz, K. A.; Matzger, A. J. Water Stability of Microporous Coordination Polymers and the Adsorption of Pharmaceuticals from Water. Langmuir 2010, 26, 17198-17202.

(26) Küsgens, P.; Rose, M.; Senkovska, I.; Fröde, H.; Henschel, A.; Siegle, S.; Kaskel, S. Characterization of Metal-Organic Frameworks by Water Adsorption. Microporous Mesoporous Mater. 2009, 120, 325330.

(27) Horcajada, P.; Surblé, S.; Serre, C.; Hong, D.-Y.; Seo, Y.-K.; Chang, J.-S.; Grenèche, J.-M.; Margiolaki, I.; Férey, G. Synthesis and Catalytic Properties of MIL-100(Fe), an iron(III) Carboxylate with Large Pores. Chem. Commun. 2007, 2820-2822.

(28) Liu, Y.; Eubank, J. F.; Cairns, A. J.; Eckert, J.; Kravtsov, V. C.; Luebke, R.; Eddaoudi, M. Assembly of Metal-Organic Frameworks (MOFs) Based on Indium-Trimer Building Blocks: A Porous MOF with Soc Topology and High Hydrogen Storage. Angew. Chem., Int. Ed. 2007, 46, 3278-3283. 
(29) Chevreau, H.; Permyakova, A.; Nouar, F.; Fabry, P.; Livage, C.; Ragon, F.; Garcia-Marquez, A.; Devic, T.; Steunou, N.; Serre, C.; Horcajada, P. Synthesis of the Biocompatible and Highly Stable MIL127(Fe): From Large Scale Synthesis to Particle Size Control. CrystEngComm 2016, 18, 4094-4101.

(30) Ghosh, P.; Colón, Y. J.; Snurr, R. Q. Water Adsorption in UiO66: The Importance of Defects. Chem. Commun. 2014, 50, 1132911331.

(31) Cavka, J. H.; Jakobsen, S.; Olsbye, U.; Guillou, N.; Lamberti, C.; Bordiga, S.; Lillerud, K. P. A New Zirconium Inorganic Building Brick Forming Metal Organic Frameworks with Exceptional Stability. J. Am. Chem. Soc. 2008, 130, 13850-13851.

(32) Hartlieb, K. J.; Ferris, D. P.; Holcroft, J. M.; Kandela, I.; Stern, C. L.; Nassar, M. S.; Botros, Y. Y.; Stoddart, J. F. Encapsulation of Ibuprofen in CD-MOF and Related Bioavailability Studies. Mol. Pharm. 2017, 14, 1831-1839.

(33) Bhadra, B. N.; Ahmed, I.; Kim, S.; Jhung, S. H. Adsorptive Removal of Ibuprofen and Diclofenac from Water Using MetalOrganic Framework-Derived Porous Carbon. Chem. Eng. J. 2017, 314, $50-58$.

(34) García Márquez, A.; Demessence, A.; Platero-Prats, A. E.; Heurtaux, D.; Horcajada, P.; Serre, C.; Chang, J.-S.; Férey, G.; De La Peña-O’Shea, V. A.; Boissière, C.; Grosso, D.; Sanchez, C. Green Microwave Synthesis of MIL-100(Al, Cr, Fe) Nanoparticles for ThinFilm Elaboration. Eur. J. Inorg. Chem. 2012, 100, 5165-5174.

(35) Singco, B.; Liu, L.-H.; Chen, Y.-T.; Shih, Y.-H.; Huang, H.-Y.; Lin, C.-H. Approaches to Drug Delivery: Confinement of Aspirin in MIL-100(Fe) and Aspirin in the de Novo Synthesis of Metal-Organic Frameworks. Microporous Mesoporous Mater. 2016, 223, 254-260.

(36) Horcajada, P.; Chalati, T.; Serre, C.; Gillet, B.; Sebrie, C.; Baati, T.; Eubank, J. F.; Heurtaux, D.; Clayette, P.; Kreuz, C.; Chang, J.-S.; Hwang, Y. K.; Marsaud, V.; Bories, P.-N.; Cynober, L.; Gil, S.; Férey, G.; Couvreur, P.; Gref, R. Porous Metal-Organic-Framework Nanoscale Carriers as a Potential Platform for Drug Delivery and Imaging. Nat. Mater. 2010, 9, 172-178.

(37) Rojas, S.; Carmona, F. J.; Maldonado, C. R.; Barea, E.; Navarro, J. A. R. RAPTA-C Incorporation and Controlled Delivery from MIL100(Fe) Nanoparticles. New J. Chem. 2016, 40, 5690-5694.

(38) Hailili, R.; Wang, L.; Qv, J.; Yao, R.; Zhang, X. M.; Liu, H. Planar Mn4O Cluster Homochiral Metal-Organic Framework for HPLC Separation of Pharmaceutically Important ( \pm )-Ibuprofen Racemate. Inorg. Chem. 2015, 54, 3713-3715.

(39) Bueno-Perez, R.; Martin-Calvo, A.; Gómez-Álvarez, P.; Gutiérrez-Sevillano, J. J.; Merkling, P. J.; Vlugt, T. J. H.; van Erp, T. S.; Dubbeldam, D.; Calero, S. Enantioselective Adsorption of Ibuprofen and Lysine in Metal-organic Frameworks. Chem. Commun. 2014, 50, 10849-10852.

(40) Paudel, K. S.; Milewski, M.; Swadley, C. L.; Brogden, N. K.; Ghosh, P.; Stinchcomb, A. L. Challenges and Opportunities in Dermal/transdermal Delivery. Ther. Delivery 2010, 1, 109-131.

(41) Chabri, F.; Bouris, K.; Jones, T.; Barrow, D.; Hann, A.; Allender, C.; Brain, K.; Birchall, J. Microfabricated Silicon Microneedles for Nonviral Cutaneous Gene Delivery. Br. J. Dermatol. 2004, 150, 869877.

(42) Sapino, S.; Oliaro-bosso, S.; Zonari, D.; Zattoni, A.; Ugazio, E. Mesoporous Silica Nanoparticles as a Promising Skin Delivery System for Methotrexate. Int. J. Pharm. 2017, 530, 239-248.

(43) Orellana-Tavra, C.; Marshall, R. J.; Baxter, E. F.; Lázaro, I. A.; Tao, A.; Cheetham, A. K.; Forgan, R. S.; Fairen-Jimenez, D. Drug Delivery and Controlled Release from Biocompatible Metal-organic Frameworks Using Mechanical Amorphization. J. Mater. Chem. B 2016, 7697-7707.

(44) Abánades Lázaro, I.; Haddad, S.; Sacca, S.; Orellana-Tavra, C.; Fairen-Jimenez, D.; Forgan, R. S. Selective Surface PEGylation of UiO66 Nanoparticles for Enhanced Stability, Cell Uptake, and $\mathrm{pH}$ Responsive Drug Delivery. Chem 2017, 2, 561-578.

(45) Tamames-Tabar, C.; Cunha, D.; Imbuluzqueta, E.; Ragon, F.; Serre, C.; Blanco-Prieto, M. J.; Horcajada, P. Cytotoxicity of
Nanoscaled Metal-organic Frameworks. J. Mater. Chem. B 2014, 2, $262-271$.

(46) Hu, Q.; Yu, J.; Liu, M.; Liu, A.; Dou, Z.; Yang, Y. A Low Cytotoxic Cationic Metal-Organic Framework Carrier for Controllable Drug Release. J. Med. Chem. 2014, 57, 5679-5685.

(47) Lestari, W. W.; Arvinawati, M.; Martien, R.; Kusumaningsih, T. Green and Facile Synthesis of MOF and Nano MOF Containing zinc(II) and Benzen 1,3,5-Tri Carboxylate and Its Study in Ibuprofen Slow-Release. Mater. Chem. Phys. 2018, 204, 141-146.

(48) Horcajada, P.; Serre, C.; Maurin, G.; Ramsahye, N. A.; Balas, F.; Vallet-Regí, M.; Sebban, M.; Taulelle, F.; Férey, G. Flexible Porous Metal-Organic Frameworks for a Controlled Drug Delivery. J. Am. Chem. Soc. 2008, 130, 6774-6780.

(49) Higuchi, W. I. Analysis of Data on Medicament Release Form Ointments. J. Pharm. Sci. 1962, 51, 802-804.

(50) Vallet-Regí, M.; Balas, F.; Arcos, D. Mesoporous Materials for Drug Delivery. Angew. Chem., Int. Ed. 2007, 46, 7548-7558.

(51) Ke, F.; Yuan, Y.-P.; Qiu, L.-G.; Shen, Y.-H.; Xie, A.-J.; Zhu, J.-F.; Tian, X.-Y.; Zhang, L.-D. Facile Fabrication of Magnetic Metalorganic Framework Nanocomposites for Potential Targeted Drug Delivery. J. Mater. Chem. 2011, 21, 3843-3848.

(52) Tiwari, A.; Patra, H. K.; Wang, X. Advanced Materials Interfaces; Gregory, P., Ed.; Wiley-VCH: Weinheim, 2016.

(53) Dhakshinamoorthy, A.; Alvaro, M.; Chevreau, H.; Horcajada, P.; Devic, T.; Garcia, H.; Serre, C. Iron(III) Metal-organic Frameworks as Solid Lewis Acids for the Isomerization of Alfa-Pinene Oxide. Catal. Sci. Technol. 2012, 3, 324-330.

(54) Kandiah, M.; Nilsen, M. H.; Usseglio, S.; Jakobsen, S.; Olsbye, U.; Tilset, M.; Larabi, C.; Quadrelli, E. A.; Bonino, F.; Lillerud, K. P. Synthesis and Stability of Tagged UiO-66 Zr-MOFs. Chem. Mater. 2010, 22, 6632-6640.

(55) Garibay, S. J.; Cohen, S. M. Isoreticular Synthesis and Modification of Frameworks with the UiO-66 Topology. Chem. Comm. 2010, 46, 7700-7702.

(56) Rappe, A. K.; Iii, W. A. G. Charge Equilibration for Molecular Dynamics Simulations. J. Phys. Chem. 1991, 95, 3358-3363.

(57) Rappe, A. K.; Casewit, C. J.; Colwell, K. S.; Goddard, W. A., III; Skiff, W. M. UFF, a Full Periodic Table Force Field for Molecular Mechanics and Molecular Dynamics Simulations. J. Am. Chem. Soc. 1992, 114, 10024-10035.

(58) Yang, Q.; Wiersum, A. D.; Llewellyn, P. L.; Guillerm, V.; Serre, C.; Maurin, G. Functionalizing Porous Zirconium Terephthalate UiO66 (Zr) for Natural Gas Upgrading: A Computational Exploration. Chem. Commun. 2011, 47, 9603-9605.

(59) Düren, T.; Millange, F.; Férey, G.; Walton, K. S.; Snurr, R. Q. Calculating Geometric Surface Areas as a Characterization Tool for Metal-Organic Frameworks. J. Phys. Chem. C 2007, 111, 1535015356. 